American Journal of Economics and Business Administration 4 (1): 84-93, 2012

ISSN 1945-5488

(C) 2012 Science Publications

\title{
Forecasting the Stock Exchange of Thailand uses Day of the Week Effect and Markov Regime Switching GARCH
}

\author{
${ }^{1}$ Sattayatham, P., ${ }^{1}$ N. Sopipan and ${ }^{2}$ B. Premanode \\ ${ }^{1}$ School of Mathematics, Institute of Science, \\ Suranaree University of Technology, Nakhon Ratchasima 30000, Thailand \\ ${ }^{2}$ Institute of Biomedical Engineering, \\ Imperial College South Kensington Campus, London
}

\begin{abstract}
Problem statement: We forecast return and volatility of the Stock Exchange of Thailand (SET) Index. Approach: In this study, we modeled the SET Index returns using mean equation with day of the week effect and autoregressive moving-average. Next we forecast the volatility of the SET Index by using the GARCH-type model and the Markov Regime Switching GARCH (MRS-GARCH) model. Results: When we model the SET Index by the ARMA $(3,3)$ process, we find that Friday is the day of the effect of the SET Index. The empirical analysis demonstrates that the MRS-GARCH models outperform all GARCH-type models in forecasting volatility at long term horizons (two weeks and a month). Conclusion: The ARMA $(3,3)$ and the Friday is the day of the effect of the SET Index return. The MRS-GARCH models outperform at long term horizons.
\end{abstract}

Key words: Volatility forecasting, SET index, GARCH models, Markov regime switching, stock exchange, models outperform, empirical analysis

\section{INTRODUCTION}

In the time series, the stock price is transformed to return series for stationary process which looked like white noise and forecasting was possible using the mean equation. The forecasting of daily returns has led to additional research in financial literature, specifically extending the analysis of the seasonal behavior to include the day of the week effect. This seasonality has been the subject of different studies which detected empirical evidence of abnormal yield distributions based upon the day of the week. The pioneering work was carried out as used in the analysis of seasonality and can be specifically seen in Miralles and Quiros (2000), they included five dummy variables, one for each day of the week.

Nevertheless two serious problems arise with this approach. The first problem is that the residuals obtained from the regression model can be autocorrelated, thus creating errors in the inference. The second problem is that the variances of the residuals are not constant and possibly time-dependent.

A solution to the first type of problem can be solved by introducing the returns with a one week delay into the regression model, as used in the works by Easton and Faff (1994) and Kyimaz and Berument (2001).
Moreover, Apolinario et al. (2006) and Ulussever et al. (2011) try to solve the second problem by modeling the residuals with the ARCH model in order to correct the variability in the variance of the residuals.

In this study, we reconsidered the two problems again. For the first problem, we modeled the SET Index returns by mean equation with the day of the week effect and the autoregressive moving-average order $\mathrm{p}$ and $q$ (ARMA $(p, q)$ ). For the second problem, we model the residuals by the GARCH, EGARCH, GJRGARCH and MRS-GARCH models. Finally, we compare their performance by one day, one week, two weeks and one month.

Next, we present forecasting returns with the mean equation. Then we forecast volatility of returns and estimate parameters within-sample evaluation results. Moreover, statistical loss functions are described and out-of-sample forecasting performance of various models is discussed.

\section{MATERIALS AND METHODS}

Forecasting financial returns: Let $\left\{\mathrm{P}_{\mathrm{t}}\right\}$ denote the series of the financial price at time $t$ and the returns for each market $\left\{r_{t}\right\}_{t>0}$ be a sequence of random variables

Corresponding Author: Sopipan, N., School of Mathematics, Institute of Science, Suranaree University of Technology,

Nakhon Ratchasima 30000, Thailand 
on a probability space $(\Omega, F, P)$. The index t denotes the daily closing $\mathrm{R}$ observations with $\mathrm{t}=-\mathrm{R}+1, \ldots, 0$. The sample period consists of an estimation (or in-sample) period with $n$ observations and an evolution (or out-ofsample) period with $n$ observations $(t=1, \ldots, n)$, let $r_{t}$ be the logarithmic return (in percent) on the financial price at time t, i.e. Eq. 1:

$$
r_{t}=100 \cdot \ln \left(\frac{P_{t}}{P_{t-1}}\right)
$$

To put the volatility models in proper perspective, it is informative to consider the conditional mean and variance of given, that is:

$$
\begin{aligned}
& \mu_{t}=E\left(r_{t} \mid F_{t-1}\right) \\
& h_{t}=\operatorname{Var}\left(r_{t} \mid F_{t-1}\right)=E\left[\left(r_{t}-\mu_{t}\right)^{2} \mid F_{t-1}\right]
\end{aligned}
$$

where, $F_{t-1}$ refers to information up to time $t-1$. Typically, $\mathrm{F}_{\mathrm{t}-1}$ consists of all linear functions of the past returns. Therefore, the equation for $\mu_{\mathrm{t}}$ in Eq. 2 should be simple and we assume that $r_{t}$ follows a simple time series model such as a stationary $\operatorname{ARMA}(\mathrm{p}, \mathrm{q})$ model which includes five dummy variables, one for each day of the week, such that Eq. 3:

$$
\begin{aligned}
r_{t}= & \mu_{t}+\varepsilon_{t} \\
\mu_{t}= & \beta_{1} D_{1 t}+\beta_{2} D_{2 t}+\beta_{3} D_{3 t}+\beta_{4} D_{4 t}+\beta_{5} D_{5 t} \\
& +\sum_{i=1}^{p} \phi_{i} r_{t-i}-\sum_{i=1}^{q} \theta_{i} \varepsilon_{t-i}
\end{aligned}
$$

where, $D_{j t}, j=1, \ldots, 5$ are dummy variables which take on the value of 1 if the corresponding return of the day it is a Monday, Tuesday, Wednesday, Thursday or Friday, respectively and 0 otherwise.

Let $\beta_{j}, j=1, \ldots, 5$ are coefficients which represent the average return for each day of the week $\phi_{i},=1, \ldots, p$ and $\theta_{i}, i=1, \ldots, q$, are coefficients which represent the $\operatorname{ARMA}(p, q)$.

Forecasting financial volatility: We allow variance of errors to be time dependent to include a conditional heteroskedasticity that captures time variations of variances in stock returns Eq. 3. The GARCH-type models in our consideration are $\operatorname{GARCH}(1,1)$, EGARCH $(1,1)$, GJR-GARCH $(1,1)$ and MRSGARCH. For notation conveniences, we shall present some basic definitions of these models.

The GARCH $(1,1)$ model in the series of the returns rt in Eq. 3 can be written as Eq. 4:

$$
\begin{aligned}
& r_{t}=\mu_{t}+\varepsilon_{t}=\mu_{t}+\eta_{t} \sqrt{h_{t}} \\
& h_{t}=\alpha_{0}+\alpha_{1} \varepsilon_{t-1}^{2}+\beta_{1} h_{t-1}
\end{aligned}
$$

where, $\mathrm{a}_{0}>0, \mathrm{a}_{1} \geq 0$ and $\beta_{1} \geq 0$ are assumed to be nonnegative real constants to ensure that $h_{t} \geq 0$. We assume $\mathrm{n}_{\mathrm{t}}$ is an i.i.d. Process with zero mean and unit variances.

The parameters of the GARCH model are generally considered as constants. But, the movement of financial returns between recession and expansion may result in the variation volatility. Gray (1996) extended the GARCH model to the MRS-GARCH model in order to capture regime changes in volatility with unobservable state variables. It was assumed that those unobservable state variables satisfy the first order of the Markov Chain process.

The MRS-GARCH model represented as the variance of the residual term is not constant through time with only two regimes and distributed as $\varepsilon_{\mathrm{t}} \sim$ i.i.d. $\left(0, \mathrm{~h}_{\mathrm{t}, \mathrm{s}}\right)$ and defined:

$$
\begin{aligned}
& \mathrm{r}_{\mathrm{t}}=\mu_{\mathrm{t}}+\varepsilon_{\mathrm{t}}, \varepsilon_{\mathrm{t}}=\eta_{\mathrm{t}} \sqrt{\mathrm{h}_{\mathrm{t}, \mathrm{S}_{\mathrm{t}}}} \\
& \mathrm{h}_{\mathrm{t}, \mathrm{S}_{\mathrm{t}}}=\alpha_{0, \mathrm{~S}_{\mathrm{t}}}+\alpha_{1, \mathrm{~S}_{\mathrm{t}}} \varepsilon_{\mathrm{t}-1}^{2}+\beta_{1, \mathrm{~S}_{\mathrm{t}}} \mathrm{h}_{\mathrm{t}-1}
\end{aligned}
$$

where, $S_{t}=1$ or $2, h_{t, s}$ is the volatility under regime $S_{t}$ on $F_{t-1}$. Also $\mu_{t}$ and $h_{t, S t}$ are measurable functions of $F_{t-\tau}$ for $\tau \leq \mathrm{t}$. In order to ensure the positivity of the conditional variance, we impose the restrictions $\alpha_{0, s_{\mathrm{t}}}>0, \alpha_{1, \mathrm{~s}_{\mathrm{t}}} \geq 0$ and $\beta_{1 . \mathrm{s}_{\mathrm{t}}} \geq 0$. The sum $\alpha_{1, S_{t}}+\beta_{1, S_{t}}$ measures the persistence of a shock to the conditional variance.

The unobserved regime variable $S_{t}$ is governed by a first order Markov Chain with constant transition probabilities. Given by:

$$
\operatorname{Pr}\left(S_{t}=i \mid S_{t-1}=j\right)=p_{j i} \text { fori, } j=1,2
$$

In matrix notation Eq. 5:

$$
P=\left[\begin{array}{ll}
p_{11} & p_{21} \\
p_{12} & p_{22}
\end{array}\right]=\left[\begin{array}{cc}
p & 1-q \\
1-p & q
\end{array}\right]
$$

In the MRS-GARCH model with two regimes, Klaassen (2002) forecast volatility for k-step-ahead. Klaassen used the recursive method as in the standard GARCH model for $\mathrm{k}=1,2, \ldots, \mathrm{n}$. In order to compute the k-step-ahead volatility forecasts, we first compute a weighted average of the k-step-ahead volatility forecasts in each regime and the weights are the prediction probability $\operatorname{Pr}\left(\mathrm{S}_{\mathrm{i}+\mathrm{t}}=\mathrm{i} / \mathrm{F}_{\mathrm{t}-1}\right)$. 
Since there is no serial correlation in the returns, the k-step-ahead volatility forecast at a time depends on information at time $\mathrm{t}-1$. Let $\mathrm{h}_{\mathrm{t}, \mathrm{t}+\mathrm{k}}$ denotes the time $\mathrm{t}$ aggregated volatility forecasts for the next $\mathrm{k}$ steps. It can be calculated as follows: where indicates the step-ahead volatility forecast in the regime $\mathrm{i}$ made at time $\mathrm{t}$ and can be calculated recursively as follows Eq. 6:

$$
\begin{aligned}
& \hat{\mathrm{h}}_{\mathrm{t}, \mathrm{t}+\mathrm{k}}=\sum_{\tau=1}^{\mathrm{k}} \hat{\mathrm{h}}_{\mathrm{t}, \mathrm{t}+\tau}=\sum_{\tau=1}^{\mathrm{k}}\left[\sum_{\mathrm{i}=1}^{2} \operatorname{Pr}\left(\mathrm{S}_{\mathrm{t}+\tau}=\mathrm{i} \mid \mathrm{F}_{\mathrm{t}-1}\right) \hat{\mathrm{h}}_{\mathrm{t}, \mathrm{t}+\tau, \mathrm{S}_{\mathrm{t}+\tau}=\mathrm{i}}\right] \\
& \hat{\mathrm{h}}_{\mathrm{t}, \mathrm{t}+\tau, \mathrm{S}+\tau}=\mathrm{i}
\end{aligned}
$$

where, $h_{t, t+\tau, S t+\tau=i}$ indicates the $\tau$-step-ahead volatility forecast in the regime $\mathrm{i}$ made at time $\mathrm{t}$ and can be calculated recursively as follows Eq. 7:

$$
\begin{aligned}
\hat{h}_{\mathrm{t}, \mathrm{t}+\tau, \mathrm{S}_{\mathrm{t}+\tau}=\mathrm{i}}=\mathrm{E}_{\mathrm{t}-1}\left[\mathrm{~h}_{\mathrm{t}+\tau} \mid \mathrm{S}_{\mathrm{t}+\tau}=\mathrm{i}\right] \\
=\mathrm{E}_{\mathrm{t}-1}\left[\alpha_{0, \mathrm{~S}_{\mathrm{t}+\tau}}+\alpha_{1, \mathrm{~S}_{\mathrm{t}+\tau}} \varepsilon_{\mathrm{t}+\tau-1}^{2}+\beta_{1, \mathrm{~S}_{\mathrm{t}+\tau}} \mathrm{h}_{\mathrm{t}+\tau-1} \mid \mathrm{S}_{\mathrm{t}+\tau}=\mathrm{i}\right] \\
=\alpha_{0, \mathrm{~S}_{\mathrm{t}+\tau}=\mathrm{i}}+\alpha_{1, \mathrm{~S}_{\mathrm{t}+\tau}=\mathrm{i}} \mathrm{E}_{\mathrm{t}-1}\left[\varepsilon_{\mathrm{t}+\tau-1}^{2} \mid \mathrm{S}_{\mathrm{t}+\tau}=\mathrm{i}\right] \\
+\beta_{1, \mathrm{~S}_{\mathrm{t}+\tau}=\mathrm{i}} \mathrm{E}_{\mathrm{t}-1}\left[\mathrm{~h}_{\mathrm{t}+\tau-1} \mid \mathrm{S}_{\mathrm{t}+\tau}=\mathrm{i}\right] \\
=\alpha_{0, \mathrm{~S}_{\mathrm{t}+\tau}=\mathrm{i}}+\alpha_{1, \mathrm{~S}_{\mathrm{t}+\tau}=\mathrm{i}} \mathrm{E}_{\mathrm{t}-1}\left[\mathrm{E}_{\mathrm{t}-1}\left[\varepsilon_{\mathrm{t}+\tau-1}^{2} \mid \mathrm{S}_{\mathrm{t}+\tau-1}\right] \mid \mathrm{S}_{\mathrm{t}+\tau}=\mathrm{i}\right] \\
+\beta_{1, \mathrm{~S}_{\mathrm{t}+\tau}=\mathrm{i}} \mathrm{E}_{\mathrm{t}-1}\left[\mathrm{~h}_{\mathrm{t}+\tau-1} \mid \mathrm{S}_{\mathrm{t}+\tau}=\mathrm{i}\right] \\
=\alpha_{0, \mathrm{~S}_{\mathrm{t}+\tau}=\mathrm{i}}+\left(\alpha_{1, \mathrm{~S}_{\mathrm{t}+\tau}=\mathrm{i}}+\beta_{1, \mathrm{~S}_{\mathrm{t}+\tau}=\mathrm{i}}\right) \mathrm{E}_{\mathrm{t}-1}\left[\mathrm{~h}_{\mathrm{t}, \mathrm{t}+\tau-1} \mid \mathrm{S}_{\mathrm{t}+\tau}=\mathrm{i}\right]
\end{aligned}
$$

Also, in general the prediction probability in Eq. 6 is computed as:

$$
\left[\begin{array}{l}
\operatorname{Pr}\left(\mathrm{S}_{\mathrm{t}+\tau}=1 \mid \mathrm{F}_{\mathrm{t}-1}\right) \\
\operatorname{Pr}\left(\mathrm{S}_{\mathrm{t}+\tau}=2 \mid \mathrm{F}_{\mathrm{t}-1}\right)
\end{array}\right]=\mathrm{P}^{\tau+1}\left[\begin{array}{l}
\operatorname{Pr}\left(\mathrm{S}_{\mathrm{t}-1}=1 \mid \mathrm{F}_{\mathrm{t}-1}\right) \\
\operatorname{Pr}\left(\mathrm{S}_{\mathrm{t}-1}=2 \mid \mathrm{F}_{\mathrm{t}-1}\right)
\end{array}\right]
$$

where, $\mathrm{P}$ defined in Eq. 4 and $\operatorname{Pr}\left(\mathrm{S}_{\mathrm{t}-1}=\mathrm{i} / \mathrm{F}_{\mathrm{t}-1}\right)$ will be calculated in Eq. 12. Lastly, we compute expectation part $\mathrm{E}_{\mathrm{t}-1}\left[\mathrm{~h}_{\mathrm{t}, \mathrm{t}+\tau-1} \mid \mathrm{S}_{\mathrm{t}+\tau}=\mathrm{i}\right]$ as appeared in Eq. 7 as follows Eq. 8:

$$
\begin{aligned}
& E_{t-1}\left[h_{t, t+\tau-1} \mid S_{t+\tau}=i\right] \\
& =E_{t-1}\left[E_{t-1}\left[r_{t+\tau-1}^{2} \mid S_{t+\tau-1}=j\right]\right. \\
& \left.=\left[E_{t-1}\left[r_{t+\tau-1} \mid S_{t+\tau-1}=j\right]\right]^{2} \mid S_{t+\tau}=i\right] \\
& =E_{t-1}\left[E_{t-1}\left[r_{t+\tau-1}^{2} \mid S_{t+\tau-1}=j\right] \mid S_{t+\tau}=i\right] \\
& -E_{t-1}\left[\left[E_{t-1}\left[r_{t+\tau-1} \mid S_{t+\tau-1}=j\right]\right]^{2} \mid S_{t+\tau}=i\right]
\end{aligned}
$$

The first on the right hand side of Eq. 11 can be calculated as follows Eq. 9 and 10:

$$
\begin{aligned}
& E_{t-1}\left[E_{t-1}\left[r_{t+\tau-1}^{2} \mid S_{t+\tau-1}=j\right] \mid S_{t+\tau}=i\right] \\
= & \sum_{j=1}^{2} E_{t-1}\left[r_{t+\tau-1}^{2} \mid S_{t+\tau-1}=j\right] \cdot \operatorname{Pr}\left(S_{t+\tau-1}=j \mid S_{t+\tau}=i, F_{t-1}\right) \\
= & \sum_{j=1}^{2} E_{t-1}\left[\left(\mu_{t}+\varepsilon_{t+\tau-1}\right)^{2} \mid S_{t+\tau-1}=j\right] \\
& \cdot \operatorname{Pr}\left(S_{t+\tau-1}=j \mid S_{t+\tau}=i, F_{t-1}\right) \\
= & \sum_{j=1}^{2} E_{t-1}\left[\mu_{t}^{2}+2 \mu_{t} \varepsilon_{t+\tau-1}+\varepsilon_{t+\tau-1}^{2} \mid S_{t+\tau-1}=j\right] \\
& \cdot \operatorname{Pr}\left(S_{t+\tau-1}=j \mid S_{t+\tau}=i, F_{t-1}\right) \\
= & \sum_{j=1}^{2} \tilde{p}_{j i, t-1}\left[\mu_{t, S_{t+\tau-1}=j}^{2}+h_{t+\tau-1, S_{t+\tau-1}=j}\right]
\end{aligned}
$$

Where:

$$
\begin{aligned}
\tilde{\mathrm{p}}_{\mathrm{j} i \mathrm{t}-1} & =\operatorname{Pr}\left(\mathrm{S}_{\mathrm{t}+\tau-1}=\mathrm{j} \mid \mathrm{S}_{\mathrm{t}+\tau}=\mathrm{i}, \mathrm{F}_{\mathrm{t}-1}\right) \\
& =\frac{\mathrm{p}_{\mathrm{ji}} \operatorname{Pr}\left(\mathrm{S}_{\mathrm{t}+\tau-1}=\mathrm{j} \mid \mathrm{F}_{\mathrm{t}-1}\right)}{\operatorname{Pr}\left(\mathrm{S}_{\mathrm{t}+\tau}=\mathrm{i} \mid \mathrm{F}_{\mathrm{t}-1}\right)}
\end{aligned}
$$

Similarly, the second term on the right hand side in Eq. 8 is equal to:

$$
\begin{aligned}
& E_{t-1}\left[\left[E_{t-1}\left[r_{t+\tau-1} \mid S_{t+\tau-1}=j\right]\right]^{2} \mid S_{t+\tau}=i\right] \\
& =\sum_{j=1}^{2} \tilde{p}_{j i, t-1}\left[\mu_{t}, s_{t+\tau-1}=j\right]^{2}
\end{aligned}
$$

Substituting Eq. 9 and 11 into Eq. 8, one gets:

$$
\begin{aligned}
\mathrm{E}_{\mathrm{t}-1}\left(\hat{\mathrm{h}}_{\mathrm{t}, \mathrm{t}+\tau-1} \mid \mathrm{S}_{\mathrm{t}+\tau}=\mathrm{i}\right) & =\sum_{\mathrm{j}=1}^{2} \tilde{\mathrm{p}}_{\mathrm{ji}, \mathrm{t}-1}\left[\mu_{\mathrm{t}, \mathrm{S}_{\mathrm{t}+\tau-1}=\mathrm{j}}^{2}+\mathrm{h}_{\mathrm{t}+\tau-1, \mathrm{~S}_{\mathrm{t}+\tau-1}=\mathrm{j}}\right] \\
& -\sum_{\mathrm{j}=1}^{2} \tilde{\mathrm{p}}_{\mathrm{ji}, \mathrm{t}-1}\left[\mu_{\mathrm{t}, \mathrm{S}_{\mathrm{t} t \tau-1}=\mathrm{j}}\right]^{2}
\end{aligned}
$$

Now we are ready to compute those regime probabilities $p_{i t}=\operatorname{Pr}\left(S_{t}=i \mid F_{t-1}\right)$ for $i=1,2$ in Eq. 10. In order to compute the regime probabilities, we denote $f_{1 t}$ $=\mathrm{f}\left(\mathrm{r}_{\mathrm{t}} \mid \mathrm{S}_{\mathrm{t}}=1, \mathrm{~F}_{\mathrm{t}-1}\right) \mathrm{f}_{2 \mathrm{t}}=\mathrm{f}\left(\mathrm{r}_{\mathrm{t}} \mid \mathrm{S}_{\mathrm{t}}=2 \mathrm{~F}_{\mathrm{t}-1}\right)$. Then, the conditional distribution of return series $r_{t}$ becomes a mixture-of-distribution model. Which the mixing variable is a regime probability $\mathrm{p}_{\mathrm{it}}$. That is:

$$
r_{t} \mid F_{t-1} \sim\left\{\begin{array}{c}
f\left(r_{t} \mid S_{t}=1, F_{t-1}\right) \quad \text { with probability } p_{1 t} \\
f\left(r_{t} \mid S_{t}=2, F_{t-1}\right) \text { with probability } p_{2 t}=1-p_{1 t}
\end{array}\right.
$$

Here $\operatorname{Pr}\left(\mathrm{S}_{\mathrm{t}-1}=\mathrm{j} \mid \mathrm{F}_{\mathrm{t}-1}\right)$ denotes one of the assumed conditional distributions for errors, i.e. Normal distribution (N), Student-t distribution with single (t) or double (2t) degree of freedom, or Generalized Error Distributions (GED). 
We shall compute regime probabilities recursively by following two steps (Kim and Nelson, 1999).

Step 1, given the $P R\left(S_{t-1}=j \mid F_{t-1}\right)$ at the end of the time $\mathrm{t}-1$, the regime probabilities $\mathrm{p}_{\mathrm{it}} \operatorname{Pr}\left(\mathrm{S}_{\mathrm{t}-1}=\mathrm{j} \mid \mathrm{F}_{\mathrm{t}-1}\right)$ is computed as:

$$
\operatorname{Pr}\left(S_{t}=\mathrm{i} \mid \mathrm{F}_{\mathrm{t}-1}\right)=\sum_{\mathrm{j}=1}^{2} \operatorname{Pr}\left(\mathrm{S}_{\mathrm{t}}=\mathrm{i}, \mathrm{S}_{\mathrm{t}-1}=\mathrm{j} \mid \mathrm{F}_{\mathrm{t}-1}\right)
$$

Since the current regime $\left(\mathrm{S}_{\mathrm{t}}\right)$ only depends on the regime one period ago $\left(\mathrm{S}_{\mathrm{t}-1}\right)$, then:

$$
\begin{aligned}
& \operatorname{Pr}\left(\mathrm{S}_{\mathrm{t}}=\mathrm{i} \mid \mathrm{F}_{\mathrm{t}-1}\right)=\sum_{\mathrm{j}=1}^{2} \operatorname{Pr}\left(\mathrm{S}_{\mathrm{t}}=\mathrm{i}, \mathrm{S}_{\mathrm{t}-1}=\mathrm{j} \mid \mathrm{F}_{\mathrm{t}-1}\right) \\
& =\sum_{\mathrm{j}=1}^{2} \operatorname{Pr}\left(\mathrm{S}_{\mathrm{t}}=\mathrm{i} \mid \mathrm{S}_{\mathrm{t}-1}=\mathrm{j}\right) \operatorname{Pr}\left(\mathrm{S}_{\mathrm{t}-1}=\mathrm{j} \mid \mathrm{F}_{\mathrm{t}-1}\right) \\
& =\sum_{\mathrm{j}=1}^{2} \mathrm{p}_{\mathrm{ji}} \operatorname{Pr}\left(\mathrm{S}_{\mathrm{t}-1}=\mathrm{j} \mid \mathrm{F}_{\mathrm{t}-1}\right)
\end{aligned}
$$

Step 2, once $r_{t}$ observed at the end of time $t$, we can update the probability term in the following way:

$$
\operatorname{Pr}\left(S_{t}=i \mid F_{t}\right)=\operatorname{Pr}\left(S_{t}=i \mid r_{t}, F_{t-1}\right)=\frac{f\left(r_{t}, S_{t}=i \mid F_{t-1}\right)}{f\left(r_{t} \mid F_{t-1}\right)}
$$

where, $F_{t}=\left\{F_{t-1}, r_{t}\right\}$.

Let $f\left(r_{t}, S_{t}=i / F_{t-1}\right)$ is the joint density of returns and unobserved at state for $\mathrm{i}=1,2$ and it can be written as follows:

$$
\begin{aligned}
\mathrm{f}\left(\mathrm{r}_{\mathrm{t}}, \mathrm{S}_{\mathrm{t}}=\mathrm{i} \mid \mathrm{F}_{\mathrm{t}-1}\right) & =\mathrm{f}\left(\mathrm{r}_{\mathrm{t}} \mid \mathrm{S}_{\mathrm{t}}=\mathrm{i}, \mathrm{F}_{\mathrm{t}-1}\right) \mathrm{f}\left(\mathrm{S}_{\mathrm{t}}=\mathrm{i} \mid \mathrm{F}_{\mathrm{t}-1}\right) \\
& =\mathrm{f}\left(\mathrm{r}_{\mathrm{t}} \mid \mathrm{S}_{\mathrm{t}}=\mathrm{i}, \mathrm{F}_{\mathrm{t}-1}\right) \operatorname{Pr}\left(\mathrm{S}_{\mathrm{t}}=\mathrm{i} \mid \mathrm{F}_{\mathrm{t}-1}\right)
\end{aligned}
$$

Define $f\left(r_{t} / F_{t-1}\right)$ is a marginal density function of returns and can be constructed as follows:

$$
\begin{aligned}
f\left(r_{t} \mid F_{t-1}\right) & =\sum_{i=1}^{2} f\left(r_{t}, S_{t}=i \mid F_{t-1}\right) \\
& =\sum_{i=1}^{2} f\left(r_{t} \mid S_{t}=i, F_{t-1}\right) \operatorname{Pr}\left(S_{t}=i \mid F_{t-1}\right)
\end{aligned}
$$

We use Bayesian arguments Eq. 12:

$$
\begin{aligned}
\operatorname{Pr}\left(S_{t}=i \mid F_{t}\right) & =\frac{f\left(r_{t}, S_{t}=i \mid F_{t-1}\right)}{f\left(r_{t} \mid F_{t-1}\right)} \\
& =\frac{f\left(r_{t} \mid S_{t}=i, F_{t-1}\right) \operatorname{Pr}\left(S_{t}=i \mid F_{t-1}\right)}{\sum_{i=1}^{2} f\left(r_{t} \mid S_{t}=i, F_{t-1}\right) \operatorname{Pr}\left(S_{t}=i \mid F_{t-1}\right)} \\
= & \frac{f_{i t} p_{i t}}{\sum_{i=1}^{2} f_{i t} p_{i t}}
\end{aligned}
$$

Then, all regime probabilities $\left(\mathrm{p}_{\mathrm{it}}\right)$ can be computed by iterating these two steps. However, at the beginning of the iteration, $\operatorname{Pr}\left(\mathrm{S}_{0}=\mathrm{i} / \mathrm{F}_{0}\right)$ for $\mathrm{i}=1,2$ are necessary to start iterating. We follow the technique of Hamilton (1989; 1990) by setting:

$$
\begin{aligned}
& \pi_{1}=\operatorname{Pr}\left(\mathrm{S}_{0}=1 \mid \mathrm{F}_{0}\right)=\frac{1-\mathrm{q}}{2-\mathrm{p}-\mathrm{q}}, \\
& \pi_{2}=\operatorname{Pr}\left(\mathrm{S}_{0}=2 \mid \mathrm{F}_{0}\right)=\frac{1-\mathrm{p}}{2-\mathrm{p}-\mathrm{q}}
\end{aligned}
$$

Given initial values for regime probabilities, conditional mean and conditional variance in each regime, the parameters of the MRS-GARCH model can be obtained by maximizing numerically the loglikelihood function Marcucci (2005). The loglikelihood function is constructed recursively similar to that in the GARCH model.

\section{RESULTS}

The data set was used the daily closing prices of the SET Index $\mathrm{P}_{\mathrm{t}}$ over the period 3/01/2007 through $30 / 03 / 2011$ ( $\mathrm{t}=1, \ldots, 1,038$ observations). The data set is obtained from the Stock Exchange of Thailand. The data set is divided into in-sample ( $\mathrm{R} 977$ observations) and out-of-sample ( $n=61$ observations). The plot $p_{t}$ of and its $\log$ returns series $r_{t}$ (Eq. 1) are given in Fig. 1. Plot $p_{t}$ and $r_{t}$ display the usual properties of financial data series. As expected, volatility is not constant over that period of time and exhibit volatility clustered with large changes in the index often followed by large changes and small changes often followed by small changes.

Descriptive statistics of $r_{t}$ are presented in Table 1 . As Table 1 shows, overall, $r_{t}$ has a quite small positive average return (about $0.0436 \%$ ). Standard deviation of $r_{t}$ is $1.5525 \%$. The lowest average return is observed on Monday and the highest average return occurs on Friday.

Moreover, we tested for the normality of $r_{t}$ by using the Jarque-Bera test (The Jarque-Bera Normality test is a goodness-of-fit measure of departure from normality and can be used to test which has a $x^{2}$ distribution with 2 degrees of freedom under the null hypothesis that the data is from a normal distribution. The 5\% critical value is, therefore, 5.99) under the null hypothesis $r_{t}$ is normally distributed and we find that the test statistic value is 1,758.1080 which lead us to reject the null hypothesis. So $r_{t}$ is not normally distributed. Also, the skewness and kurtosis of $r_{t}$ are -0.7189 (not equal zero) and 6.2605 (greater than 3) respectively. These values confirm that the returns are not normally distributed, namely, it has fatter tails. 
Am. J. of Economics and Business Administration 4 (1): 84-93, 2012
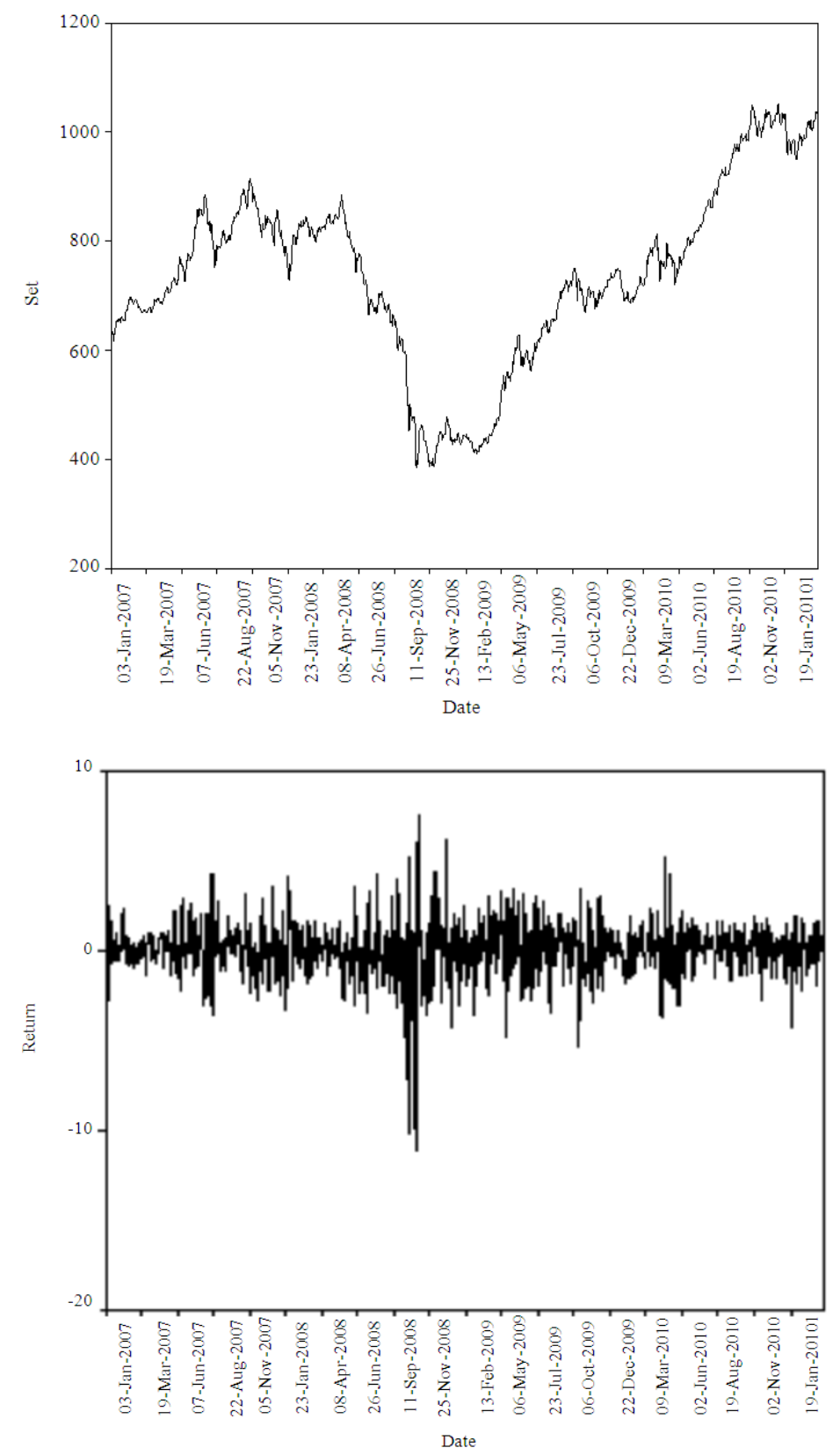

Fig. 1: Graph of (a) SET Index closing prices $\left(\mathrm{P}_{t}\right)$ and (b) logs returns series $\left(\mathrm{r}_{\mathrm{t}}\right)$ for the period 3/01/2007 through $31 / 03 / 2011$

Table 1: Descriptive statistics of SET Index log returns series $\left(\mathrm{r}_{\mathrm{t}}\right)$

\begin{tabular}{|c|c|c|c|c|c|c|}
\hline Statistic & All day & Monday & Tuesday & Wednesday & Thursday & Friday \\
\hline Mean & $0.04 \%$ & $-0.04 \%$ & $-0.02 \%$ & $0.03 \%$ & $0.03 \%$ & $0.22 \%$ \\
\hline Std. Deviation & 1. $55 \%$ & $1.98 \%$ & $1.46 \%$ & $1.37 \%$ & $1.43 \%$ & $1.48 \%$ \\
\hline Minimum & $-11.09 \%$ & $-11.09 \%$ & $-4.28 \%$ & $-7.13 \%$ & $-5.44 \%$ & $-10.10 \%$ \\
\hline Maximum & $7.55 \%$ & $7.55 \%$ & $5.29 \%$ & $3.28 \%$ & $6.10 \%$ & $4.19 \%$ \\
\hline Skewness & -0.7189 & -0.5511 & 0.2214 & -1.0215 & -0.2429 & -1.9876 \\
\hline Kurtosis & 6.2605 & 5.8511 & 1.7362 & 3.2096 & 2.7026 & 13.7500 \\
\hline Jarque-Bera Normality test & 1758. 1080 & & & & & \\
\hline Augmented Dickey-Fuller test & -30.0801 & & & & & \\
\hline
\end{tabular}


Table 2: Day of the week effect and ARMA (p, q) in mean equation of return

Panel A: Day of the week effect in mean equation of return

\begin{tabular}{lcclll}
\hline & Monday & Tuesday & Wednesday & Thursday & Friday \\
\hline$\beta$ & -0.064 & -0.038 & 0.02 & 0.014 & $0.2210^{* *}$ \\
Std. error & 0.109 & 0.106 & 0.105 & 0.106 & 0.107 \\
\hline **
\end{tabular}

** refer the significance at $95 \%$ confidence

Panel B: ARMA models parametric estimates in mean equation of return

\begin{tabular}{lcccl}
\hline Variable & Coefficient & Std. Error & t-Statistic & P-value \\
\hline AR (1) & 2.5855 & 0.0579 & 44.6244 & $0.0000^{* * *}$ \\
AR (2) & -2.4248 & 0.1121 & -21.6289 & $0.0000^{* * *}$ \\
AR (3) & 0.8289 & 0.0617 & 13.4318 & $0.0000^{* * *}$ \\
MA (1) & 2.5059 & 0.0732 & 34.2502 & $0.0000^{* * *}$ \\
MA (2) & -2.2667 & 0.1436 & -15.7891 & $0.0000^{* * *}$ \\
MA (3) & 0.7459 & 0.0799 & 9.3413 & $0.0000^{* * *}$ \\
\hline *** refer the significance at 99\%confidence
\end{tabular}

*** refer the significance at $99 \%$ confidence

Moreover, we test for the stationary of $r_{t}$ by using the Augmented Dickey-Fuller test (The Augmented DickeyFuller test is a test for a unit root in a time series sample, the null hypothesis of ADF test is that the series is nonstationary. The 1,5 and $10 \%$ critical value are -3.44 , 2.86 and -2.57 respectively). The test statistic value is 30.0801 which indicates the stationary of $r_{t}$.

Table 2 reports the day of the week effects and ARMA (p, q) for returns. Panel A of Table 2 displays the first estimated coefficients of the day of the week effect $\left(\beta_{\mathrm{I}}: \mathrm{I}=1, \ldots, 5\right)$. From Table 2 (Panel A), we found the estimated coefficients of $\beta_{\mathrm{i}}$ are almost zero. Then we test under the null hypothesis that each coefficient $\left(\beta_{\mathrm{I}}: \mathrm{I}=1, \ldots, 5\right)$ is zero. We find that the coefficient of Fridays' dummy variable is not zero significant at the $95 \%$ level and other days are insignificant. These observations suggest that only Friday is the day of the effect of the SET Index.

Panel B displays the estimated coefficients of the ARMA process and P-values. By using t-test under the null hypothesis that each coefficient AR (p) and MA (q) is zero, we found that the P-values are all zero then each coefficient is not zero significant at the $99 \%$ level. Hence the SET Index return can be modeled by the ARMA $(3,3)$ process.

The autocorrelation functions (ACF) are presented in Table 3, when we apply Ljung-Box to test serial correlation in $\mathrm{P}_{\mathrm{t}}$ and $\mathrm{r}_{\mathrm{t}}$. We use the specified lag from the first to the tenth lags and the twenty-second lag. Serial correlation in $\mathrm{P}_{\mathrm{t}}$ (column 2) confirmed as nonstationary but $r_{t}$ is stationary because of ACF values (column 5) decrease very fast when the lag increases and is confirmed by the Augmented Dickey-Fuller test in Table 1. We analyze the significance of autocorrelation in the squared mean adjusted $\left(\mathrm{r}_{\mathrm{t}}-\mu_{\mathrm{t}}\right)^{2}$ return series by using the Ljung-Box Q-test (The LjungBox Q-test is a type of statistical test of whether any of a group of autocorrelations of a time series are different from zero. The test is also distributed as a $x^{2}(q)$, where $\mathrm{q}$ is the number of lags). Since the $\mathrm{P}$ - value in column 10 is equal to zero then the squared mean adjusted return is non-stationary. Next, we apply Engle's ARCH test (The ARCH test is a test with the null hypothesis that, in the absence of ARCH components, we have $\alpha_{i}=$ 0 for all $i=1,2, \ldots, q$. The test is also distributed as $a x^{2}$ (q), where $q$ is the number of lags). The test is also distributed as a $x^{2}(q)$, where $q$ is the number of lags) (1982) to test ARCH effects of the squared mean adjusted return. The P-value in column 12 suggests the conditional heteroskedasticity.

Empirical methodology: This empirical part adopts the GARCH type and MRS-GARCH $(1,1)$ models to estimate the volatility of the $\mathrm{P}_{\mathrm{t}}$. The GARCH type models that will be considered are GARCH $(1,1)$, EGARCH (Model of EGARCH $(1,1)$ is):

$$
\ln \left(\mathrm{h}_{\mathrm{t}}\right)=\alpha_{0}+\alpha_{1}\left|\frac{\varepsilon_{\mathrm{t}-1}}{\sqrt{\mathrm{h}_{\mathrm{t}-1}}}\right|+\beta_{1} \ln \left(\mathrm{h}_{\mathrm{t}-1}\right)+\xi \frac{\varepsilon_{\mathrm{t}-1}}{\sqrt{\mathrm{h}_{\mathrm{t}-1}}}
$$

(where $\xi$ is the asymmetry parameter to capture leverage effect) and GJR-GARCH (Model of GJR$\operatorname{GARCH}(1,1)$ is:

$$
h_{t}=\alpha_{0}+\alpha_{1} \varepsilon_{t-1}^{2}\left(1-I_{\left\{\varepsilon_{t-1}>0\right\}}\right)+\beta_{1} h_{t-1}+\xi \varepsilon_{t-1}^{2}\left(I_{\left\{\varepsilon_{t-1}>0\right\}}\right)
$$

(where $I_{\{\varepsilon t-1\}}>0$ is equal to one when $\varepsilon_{t-1}$ is greater than zero and another is zero) (Klaanssen, 2002) (1,1). In order to account for the fat tails feature of financial returns, we consider three different distributions for the innovations: Normal (N), Student-t (t) and Generalized Error Distributions (GED).

Garch type models: Table 4, presents and estimation of the results for GARCH type models. It is clear from the table that almost all parameter estimates are highly significant at $1 \%$. However, the asymmetry effect term $\xi$ in EGARCH models is significantly different from zero, which indicates unexpected negative returns implying higher conditional variance as compared to the same size positive returns.

All models display strong persistence in volatility ranging from 0.8950 to 0.9521 , that is, volatility is likely to remain high over several price periods once it increases.

Markov regime switching garch models: Estimation results and summary statistics of MRS-GARCH models are presented in Table 5. Most parameter estimates in MRS-GARCH are significantly different from zero at least at the $95 \%$ confidence level. 
Am. J. of Economics and Business Administration 4 (1): 84-93, 2012

Table 3: ACF of SET Index closed price $\left(\mathrm{P}_{t}\right), \log$ returns series $\left(\mathrm{r}_{\mathrm{t}}\right)$, squared mean adjusted return and results for Engle's ARCH Test

\begin{tabular}{|c|c|c|c|c|c|c|c|c|c|c|c|}
\hline \multirow[b]{2}{*}{ Lag } & \multicolumn{3}{|c|}{ ACF of $P_{t}$} & \multicolumn{3}{|c|}{$\mathrm{ACF}$ of $\mathrm{r}_{\mathrm{t}}$} & \multicolumn{3}{|c|}{ ACF of $\left(r_{t}-\mu_{t}\right)^{2}$} & \multicolumn{2}{|c|}{ Engle's ARCH test } \\
\hline & $\mathrm{ACF}$ & LBQ Test & $\mathrm{P}$-value & $\mathrm{ACF}$ & LBQ Test & P-value & $\mathrm{ACF}$ & LBQ Test & P-value & ARCH Test & $\mathrm{P}$-value \\
\hline 1 & 0.9962 & 0.1033 & 0.0000 & 0.0672 & 4.69380 & 0.0303 & 0.2872 & 85.71260 & 0.0000 & 85.48390 & 0.0000 \\
\hline 2 & 0.9922 & 0.2059 & 0.0000 & 0.0639 & 8.94150 & 0.0114 & 0.3126 & 187.3116 & 0.0000 & 145.2592 & 0.0000 \\
\hline 3 & 0.9881 & 0.3077 & 0.0000 & 0.0111 & 9.06890 & 0.0284 & 0.2141 & 235.0199 & 0.0000 & 152.0515 & 0.0000 \\
\hline 4 & 0.9839 & 0.4088 & 0.0000 & -0.0175 & 9.38790 & 0.0521 & 0.1656 & 263.5800 & 0.0000 & 152.5688 & 0.0000 \\
\hline 5 & 0.9798 & 0.5091 & 0.0000 & -0.0261 & 10.0980 & 0.0725 & 0.2031 & 306.5847 & 0.0000 & 162.1801 & 0.0000 \\
\hline 6 & 0.9758 & 0.6087 & 0.0000 & -0.0844 & 17.5358 & 0.0075 & 0.1170 & 320.8663 & 0.0000 & 161.9628 & 0.0000 \\
\hline 7 & 0.9723 & 0.7077 & 0.0000 & 0.0106 & 17.6543 & 0.0136 & 0.0808 & 327.6824 & 0.0000 & 162.9380 & 0.0000 \\
\hline 8 & 0.9688 & 0.8061 & 0.0000 & -0.0447 & 19.7439 & 0.0113 & 0.1018 & 338.5187 & 0.0000 & 164.0005 & 0.0000 \\
\hline 9 & 0.9656 & 0.9039 & 0.0000 & 0.0634 & 23.9630 & 0.0044 & 0.1991 & 380.0243 & 0.0000 & 187.2375 & 0.0000 \\
\hline 10 & 0.9621 & 1.0011 & 0.0000 & 0.0870 & 31.8949 & 0.0004 & 0.2701 & 456.4668 & 0.0000 & 217.0212 & 0.0000 \\
\hline 22 & 0.9113 & 2.1086 & 0.0000 & -0.0038 & 64.5758 & 0.0000 & 0.0168 & 726.4272 & 0.0000 & 256.9269 & 0.0000 \\
\hline
\end{tabular}

Table 4: Summary results of GARCH type models

\begin{tabular}{|c|c|c|c|c|c|c|c|c|c|}
\hline \multirow[b]{2}{*}{ Parameter } & \multicolumn{3}{|l|}{ GARCH } & \multicolumn{3}{|l|}{ EGARCH } & \multicolumn{3}{|l|}{ GJR-GARCH } \\
\hline & $\mathrm{N}$ & $\mathrm{t}$ & GED & $\mathrm{N}$ & $\mathrm{t}$ & GED & $\mathrm{N}$ & $\mathrm{t}$ & GED \\
\hline $\mathrm{a}_{0}$ & $0.1318 * * *$ & $0.1593^{* * * *}$ & $0.1476^{* * * *}$ & $-0.1605 * * *$ & -0.1612 *** & $-0.1628^{* * *}$ & $0.1576^{* *}$ & $0.1828^{* * * *}$ & $0.1715^{* * * *}$ \\
\hline Std.err. & 0.0274 & 0.0443 & 0.0425 & 0.0224 & 0.0332 & 0.0323 & 0.0314 & 0.0472 & 0.0465 \\
\hline$a_{1}$ & 0. $1528^{* * *}$ & $0.1659 * * *$ & $0.1609^{* * *}$ & $0.2476^{* * *}$ & $0.2537 * * *$ & $0.2512 * * *$ & $0.2173 * * *$ & 0.2421 & 2320 *** \\
\hline Std. err. & 0.0211 & 0.0357 & 0.0342 & 0.0295 & 0.0463 & 0.0442 & 0.0320 & 0.0527 & 0.0507 \\
\hline$\beta_{1}$ & $0.7854 * * *$ & $0.7605^{* * *}$ & $0.7698 * *$ & $0.9521 * * *$ & 0.9446 *** & $0.9490 * * *$ & $0.7755 * * *$ & $0.7507 * * *$ & $0.7600 * * *$ \\
\hline Std.err. & 0.0206 & 0.0386 & 0.0361 & 0.0096 & 0.0154 & 0.0147 & 0.0238 & 0.0409 & 0.0391 \\
\hline$\xi$ & & & & $-0.0759 * * *$ & $-0.0890 * * *$ & $-0.0823 * * *$ & $0.0749 * * *$ & $0.0757 * * *$ & $0.0758 * * *$ \\
\hline Std.err. & & & & 0.0159 & 0.0261 & 0.0242 & 0.0217 & 0.0358 & 0.0339 \\
\hline V & & 7. $3375^{* *}$ & $1.3861 * *$ & & 7.8523 *** & $1.4351 * * *$ & & $7.6961 * * *$ & $1.4074 * * *$ \\
\hline Std.err. & 1.6342 & 0.0805 & 1.9484 & & & 0.0872 & & 1.7453 & 0.0809 \\
\hline $\log (\mathrm{L})$ & -1682.9300 & -1667.7000 & -1667.1400 & -1672.8400 & -1660.3800 & -1659.9800 & -1677.2900 & -1662.7900 & -1662.6700 \\
\hline Persistence & 0.9382 & 0.9264 & 0.9307 & 0.9521 & 0.9446 & 0.9490 & 0.8950 & 0.9096 & 0.9139 \\
\hline LBQ (22) & $\begin{array}{c}63.3245 \\
(0.0000)\end{array}$ & $\begin{array}{c}63.3245 \\
(0.0000)\end{array}$ & $\begin{array}{c}63.3245 \\
(0.0000)\end{array}$ & $\begin{array}{c}63.3245 \\
(0.0000)\end{array}$ & $\begin{array}{c}63.3245 \\
(0.0000)\end{array}$ & $\begin{array}{c}63.3245 \\
(0.0000)\end{array}$ & $\begin{array}{c}63.3245 \\
(0.0000)\end{array}$ & $\begin{array}{c}63.3245 \\
(0.0000)\end{array}$ & $\begin{array}{c}63.3245 \\
(0.0000)\end{array}$ \\
\hline $\mathrm{LBQ}^{2}(22)$ & $\begin{array}{c}673.3047 \\
(0.0000)\end{array}$ & $\begin{array}{c}673.6150 \\
(0.0000)\end{array}$ & $\begin{array}{c}673.6558 \\
(0.0000)\end{array}$ & $\begin{array}{c}671.9037 \\
(0.0000)\end{array}$ & $\begin{array}{c}672.9447 \\
(0.0000)\end{array}$ & $\begin{array}{c}672.8664 \\
(0.0000)\end{array}$ & $\begin{array}{c}672.0820 \\
(0.0000)\end{array}$ & $\begin{array}{c}672.9410 \\
(0.0000)\end{array}$ & $\begin{array}{c}672.9100 \\
(0.0000)\end{array}$ \\
\hline
\end{tabular}

*** and ** refer the significance at $99 \%$ and $95 \%$ confidence level respectively, LBQ (22) is Ljung-Box test of innovation at lag 22, LBQ $^{2}(22)$ is Ljung-Box test of squared innovation at lag 22 and P-value of the LBQ test in parentheses

Table 5: Summary results of MRS-GARCH models

\begin{tabular}{|c|c|c|c|c|c|c|c|c|}
\hline \multirow[b]{3}{*}{$\begin{array}{l}\text { Parameters } \\
\text { State i }\end{array}$} & \multicolumn{8}{|l|}{ MRS GARCH } \\
\hline & \multicolumn{2}{|l|}{$\mathrm{N}$} & \multicolumn{2}{|l|}{$\mathrm{t}$} & \multicolumn{2}{|l|}{$2 \mathrm{t}$} & \multicolumn{2}{|l|}{ GED } \\
\hline & $\begin{array}{l}\text { Low } \\
\text { volatility }\end{array}$ & $\begin{array}{l}\text { High } \\
\text { volatility }\end{array}$ & $\begin{array}{l}\text { Low } \\
\text { volatility }\end{array}$ & $\begin{array}{l}\text { High } \\
\text { volatility }\end{array}$ & $\begin{array}{l}\text { Low } \\
\text { volatility }\end{array}$ & $\begin{array}{l}\text { High } \\
\text { volatility }\end{array}$ & $\begin{array}{l}\text { Low } \\
\text { volatility }\end{array}$ & $\begin{array}{l}\text { High } \\
\text { volatility }\end{array}$ \\
\hline $\mathrm{a}_{0}(1)$ & $0.2163 * * *$ & $0.1850 * * *$ & $0.2350 * *$ & $0.1898^{* *}$ & 0.0000 & $0.1843 * *$ & 0.0000 & $0.1763 * * *$ \\
\hline Std.err. & 0.0844 & 0.0651 & 0.0893 & 0.1144 & 0.0926 & 0.1091 & 0.1090 & 0.0467 \\
\hline $\mathrm{A}_{1}^{(\mathrm{i})}$ & 0.0000 & $0.0749 * * *$ & 0.0000 & 0.0763 & $0.9027 * * *$ & 0.0746 & $0.9619^{* * *}$ & $0.0681^{* *}$ \\
\hline Std.err. & 0.0560 & 0.0180 & 0.0264 & 69.2049 & 0.0270 & 50.2277 & 0.3552 & 0.0351 \\
\hline$\beta_{0}{ }^{(\mathrm{i})}$ & $0.6052 * * *$ & $0.8845^{* * *}$ & $0.5842 * * *$ & $0.8750 * * *$ & 0.0000 & $0.7613^{* * *}$ & 0.0000 & $0.7762 * * *$ \\
\hline Std.err. & 0.1205 & 0.0299 & 0.0456 & 0.1782 & 0.0465 & 0.1771 & 0.0207 & 0.0389 \\
\hline $\mathrm{p}$ & $0.9582 * * *$ & $0.9603 * * *$ & $0.9785 * * *$ & $0.9822 * * *$ & & & & \\
\hline Std.err. & 0.0179 & 0.0105 & 0.0204 & 0.0066 & & & & \\
\hline q & $0.9737 * * *$ & $0.9776 * * *$ & $0.4409 * * *$ & $0.5696^{* * *}$ & & & & \\
\hline Std.err. & 0.0100 & 0.0202 & 0.0107 & 0.1093 & & & & \\
\hline $\mathrm{V}^{(\mathrm{i})}$ & & & $11.2518 * * *$ & $9.1414 * * *$ & 8.3746 & $1.4692 * * *$ & & \\
\hline Std.err. & & & 4.4451 & 4.2972 & 29.6785 & 0.0947 & & \\
\hline $\log (\mathrm{L})$ & -1658.0700 & -1652.6900 & -1651.180 & -1654.0600 & & & & \\
\hline$\sigma^{2}$ & 0.5479 & 1.7128 & 0.5652 & 3.8973 & 0.0000 & 1.1231 & 0.0000 & 0.9955 \\
\hline$\pi$ & 0.3862 & 0.6138 & 0.3607 & 0.6393 & 0.0370 & 0.9630 & 0.0397 & 0.9603 \\
\hline Persistence & 0.6052 & 0.8919 & 0.5842 & 0.9513 & 0.9027 & 0.8359 & 0.9619 & 0.8229 \\
\hline \multirow[t]{2}{*}{ LBQ(22) } & 62.6690 & 57.659 & 62.2970 & 55.8980 & & & & \\
\hline & $(0.0000)$ & & $(0.0000)$ & & $(0.0000)$ & & $(0.0000)$ & \\
\hline \multirow[t]{2}{*}{$\mathrm{LBQ}^{2}(22)$} & 678.9360 & 725.076 & 677.7940 & 720.355 & & & & \\
\hline & $(0.0000)$ & & $(0.0000)$ & & $(0.0000)$ & & $(0.0000)$ & \\
\hline
\end{tabular}


Am. J. of Economics and Business Administration 4 (1): 84-93, 2012

Table 6: In-sample Evaluation Results

\begin{tabular}{|c|c|c|c|c|c|c|c|c|c|c|c|c|c|c|c|c|c|c|c|c|}
\hline Models & $\mathrm{N}^{*}$ & Pers* & Aic & $\mathrm{R}^{*}$ & Sbic & $\mathrm{R}$ & Logl & $\mathrm{R}$ & Mse1 & $\mathrm{R}$ & Mse2 & $\mathrm{R}$ & Qlike & $\mathrm{R}$ & Mad1 & $\mathrm{R}$ & Mad2 & $\mathrm{R}$ & Hmse & $\mathrm{R}$ \\
\hline Garch-N & 4 & 0.9382 & 3.4533 & 13 & 3.4733 & 13 & -1682.93 & 13 & 1.1944 & 13 & 43.6818 & 13 & 1.60764 & 12 & 7.4140 & 12 & 2.6653 & 13 & 0.8357 & 13 \\
\hline Garch-t & 5 & 0.9264 & 3.4241 & 10 & 3.4491 & 6 & -1667.70 & 10 & 1.1790 & 11 & 43.1525 & 8 & 1.60786 & 13 & 7.4197 & 13 & 2.6412 & 10 & 0.8330 & 12 \\
\hline Garch-GED & 5 & 0.9307 & 3.4230 & 9 & 3.4480 & 5 & -1667.14 & 9 & 1.1830 & 12 & 43.3345 & 10 & 1.60750 & 11 & 7.4045 & 11 & 2.6472 & 12 & 0.8329 & 11 \\
\hline Egarch-N & 5 & 0.9521 & 3.4347 & 11 & 3.4597 & 7 & -1672.84 & 11 & 1.1294 & 4 & 41.4361 & 3 & 1.58851 & 3 & 7.3832 & 9 & 2.5688 & 4 & 0.8240 & 7 \\
\hline EGARCH-t & 6 & 0.9446 & 3.4112 & 5 & 3.4412 & 2 & -1660.38 & 6 & 1.1233 & 1 & 41.1859 & 1 & 1.58958 & 5 & 7.3854 & 10 & 2.5629 & 3 & 0.8239 & 6 \\
\hline EGARCH-GED & 6 & 0.9490 & 3.4104 & 4 & 3.4404 & 1 & -1659.98 & 5 & 1.1244 & 2 & 41.2950 & 2 & 1.58904 & 4 & 7.3713 & 7 & 2.5627 & 2 & 0.8229 & 5 \\
\hline GJR-GARCH-N & 5 & 0.8950 & 3.4438 & 12 & 3.4688 & 12 & -1677.29 & 12 & 1.1635 & 10 & 42.1079 & 6 & 1.59727 & 6 & 7.3687 & 6 & 2.6464 & 11 & 0.8302 & 10 \\
\hline GJR-GARCH-t & 6 & 0.9096 & 3.4161 & 8 & 3.4461 & 4 & -1662.79 & 8 & 1.1535 & 8 & 41.7429 & 4 & 1.59817 & 8 & 7.3728 & 8 & 2.6378 & 8 & 0.8293 & 9 \\
\hline GJR-GARCH-GED & 6 & 0.9139 & 3.4159 & 7 & 3.4459 & 3 & -1662.67 & 7 & 1.1559 & 9 & 41.8707 & 5 & 1.59759 & 7 & 7.3591 & 5 & 2.6384 & 9 & 0.8287 & 8 \\
\hline MRS-GARCH-N & 10 & 0.9581 & 3.4147 & 6 & 3.4647 & 11 & -1658.07 & 4 & 1.1518 & 7 & 43.1296 & 7 & 1.58837 & 2 & 7.2508 & 3 & 2.5784 & 6 & 0.8171 & 3 \\
\hline MRS-GARCH-2t & 12 & 0.8888 & 3.4047 & 1 & 3.4647 & 10 & -1651.18 & 1 & 1.1373 & 5 & 43.6584 & 12 & 1.60437 & 9 & 7.1590 & 2 & 2.5816 & 7 & 0.8095 & 2 \\
\hline MRS-GARCH-t & 11 & 0.8964 & 3.4057 & 2 & 3.4607 & 8 & -1652.69 & 2 & 1.1261 & 3 & 43.4001 & 11 & 1.60655 & 10 & 7.1021 & 1 & 2.5568 & 1 & 0.8035 & 1 \\
\hline MRS-GARCH-GED & 11 & 0.9484 & 3.4085 & 3 & 3.4635 & 9 & -1654.06 & 3 & 1.1473 & 6 & 43.1537 & 9 & 1.58770 & 1 & 7.2959 & 4 & 2.5696 & 5 & 0.8185 & 4 \\
\hline
\end{tabular}

*N=Number of Parameters, PERS=Persistence, $\mathrm{R}=$ Rank

Table 7: Result loss function of out-of-sample

Panel A: Result loss function of out-of-sample with forecasting volatility for one day ahead

\begin{tabular}{|c|c|c|c|c|c|c|c|c|c|c|c|c|c|c|}
\hline Model & MSE1 & $\mathrm{R}$ & MSE2 & $\mathrm{R}$ & QLIKE & $\mathrm{R}$ & MAD1 & $\mathrm{R}$ & MAD2 & $\mathrm{R}$ & HMSE & $\mathrm{R}$ & SR & $\mathrm{R}$ \\
\hline Garch-N & 0.9307 & 2 & 11.4131 & 6 & 2.3322 & 13 & 1.0260 & 2 & 2.178 & 2 & 14.9938 & 13 & 0.5333 & 9 \\
\hline Garch-t & 0.9386 & 3 & 11.4142 & 7 & 2.3287 & 11 & 1.0269 & 3 & 2.1793 & 3 & 14.7135 & 11 & 0.5333 & 9 \\
\hline Garch-GED & 0.9305 & 1 & 11.4087 & 5 & 2.3317 & 12 & 1.0254 & 1 & 2.1763 & 1 & 14.8922 & 12 & 0.5333 & 9 \\
\hline Egarch-N & 1.2836 & 8 & 11.3594 & 3 & 2.0482 & 6 & 1.1036 & 6 & 2.3922 & 7 & 3.8081 & 5 & 0.5667 & 3 \\
\hline Egarch-t & 1.3391 & 10 & 11.4262 & 8 & 2.0389 & 3 & 1.1123 & 9 & 2.4231 & 10 & 3.4130 & 1 & 0.5833 & 1 \\
\hline EGARCH-GED & 1.3073 & 9 & 11.3871 & 4 & 2.0423 & 4 & 1.1067 & 8 & 2.4044 & 8 & 3.6081 & 3 & 0.5833 & 1 \\
\hline GJR-GARCH-N & 1.3396 & 11 & 11.8156 & 9 & 2.0448 & 5 & 1.1127 & 10 & 2.4487 & 11 & 3.9283 & 6 & 0.5667 & 3 \\
\hline GJR-GARCH-t & 1.3835 & 13 & 11.9325 & 13 & 2.0333 & 1 & 1.1200 & 13 & 2.4790 & 13 & 3.5696 & 2 & 0.5500 & 7 \\
\hline GJR-GARCH-GED & 1.3627 & 12 & 11.8783 & 11 & 2.0364 & 2 & 1.1164 & 11 & 2.4653 & 12 & 3.6997 & 4 & 0.5500 & 7 \\
\hline MRS-GARCH-N & 1.2383 & 4 & 11.1717 & 1 & 2.1023 & 8 & 1.1046 & 7 & 2.3802 & 6 & 4.4324 & 8 & 0.5000 & 12 \\
\hline MRS-GARCH-2t & 1.2827 & 7 & 11.8513 & 10 & 2.1618 & 9 & 1.0748 & 4 & 2.3403 & 4 & 8.2194 & 9 & 0.5667 & 3 \\
\hline MRS-GARCH-t & 1.2797 & 6 & 11.2014 & 2 & 2.0985 & 7 & 1.1178 & 12 & 2.4106 & 9 & 4.2068 & 7 & 0.4833 & 13 \\
\hline MRS-GARCH-GED & 1.2437 & 5 & 11.9301 & 12 & 2.1635 & 10 & 1.0756 & 5 & 2.3517 & 5 & 8.3499 & 10 & 0.5667 & 3 \\
\hline
\end{tabular}

Panel B: Result loss function of out-of-sample with forecasting volatility for five days ahead. (A week)

\begin{tabular}{|c|c|c|c|c|c|c|c|c|c|c|c|c|c|c|}
\hline Model & MSE1 & $\mathrm{R}$ & MSE2 & $\mathrm{R}$ & QLIKE & $\mathrm{R}$ & MAD1 & $\mathrm{R}$ & MAD2 & $\mathrm{R}$ & HMSE & $\mathrm{R}$ & SR & $\mathrm{R}$ \\
\hline Garch-N & 1.3612 & 12 & 39.236 & 12 & 4.3247 & 12 & 1.1097 & 6 & 5.266 & 8 & 1.5169 & 13 & 0.7667 & 11 \\
\hline Garch-t & 1.3653 & 13 & 39.0978 & 11 & 4.3272 & 13 & 1.1234 & 10 & 5.3199 & 10 & 1.4435 & 11 & 0.7667 & 11 \\
\hline Garch-GED & 1.3605 & 11 & 39.0643 & 10 & 4.3243 & 11 & 1.1135 & 8 & 5.277 & 9 & 1.476 & 12 & 0.7667 & 11 \\
\hline Egarch-N & 0.9829 & 3 & 31.3583 & 8 & 4.1335 & 3 & 0.8642 & 3 & 4.2087 & 3 & 0.58 & 8 & 0.8833 & 3 \\
\hline Egarch-t & 0.9769 & 2 & 29.5375 & 6 & 4.1243 & 1 & 0.8485 & 1 & 4.1154 & 1 & 0.5291 & 6 & 0.9167 & 1 \\
\hline Egarch-GED & 0.9753 & 1 & 30.3812 & 7 & 4.1269 & 2 & 0.8528 & 2 & 4.1483 & 2 & 0.5546 & 7 & 0.9000 & 2 \\
\hline Gjr-garch-N & 1.0412 & 6 & 26.2744 & 2 & 4.2308 & 7 & 1.1102 & 7 & 5.1685 & 6 & 0.429 & 3 & 0.8500 & 4 \\
\hline Gjr-garch-t & 1.0374 & 5 & 26.6931 & 3 & 4.2394 & 9 & 1.1384 & 11 & 5.3234 & 11 & 0.4225 & 1 & 0.8500 & 4 \\
\hline Gjr-garch-ged & 1.0342 & 4 & 26.2502 & 1 & 4.2329 & 8 & 1.1204 & 9 & 5.2264 & 7 & 0.4229 & 2 & 0.8500 & 4 \\
\hline Mrs-garch-n & 1.2209 & 7 & 36.7342 & 9 & 4.2182 & 5 & 1.206 & 12 & 6.044 & 12 & 0.4883 & 4 & 0.8333 & 8 \\
\hline Mrs-garch-2t & 1.2774 & 9 & 28.8287 & 5 & 4.2184 & 6 & 0.9939 & 5 & 4.6311 & 5 & 0.6579 & 10 & 0.8333 & 8 \\
\hline Mrs-garch-t & 1.2637 & 8 & 39.9566 & 13 & 4.2505 & 10 & 1.2768 & 13 & 6.4067 & 13 & 0.5125 & 5 & 0.8500 & 4 \\
\hline Mrs-garch-ged & 1.2775 & 10 & 27.5975 & 4 & 4.2139 & 4 & 0.9815 & 4 & 4.5268 & 4 & 0.6421 & 9 & 0.8000 & 10 \\
\hline
\end{tabular}

Panel C: Result loss function of out-of-sample with forecasting volatility for ten days ahead. (Two weeks)

\begin{tabular}{|c|c|c|c|c|c|c|c|c|c|c|c|c|c|c|}
\hline Model & MSE1 & $\mathrm{R}$ & MSE2 & $\mathrm{R}$ & QLIKE & $\mathrm{R}$ & MAD1 & $\mathrm{R}$ & MAD2 & $\mathrm{R}$ & HMSE & $\mathrm{R}$ & SR & $\mathrm{R}$ \\
\hline Garch-N & 1.9098 & 7 & 83.8490 & 3 & 5.2852 & 7 & 1.6278 & 6 & 9.11900 & 6 & 0.5595 & 10 & 0.7667 & 12 \\
\hline Garch-t & 2.0007 & 9 & 90.8608 & 6 & 5.3063 & 10 & 1.703 & 9 & 9.67070 & 8 & 0.5519 & 8 & 0.7500 & 13 \\
\hline Garch-ged & 1.9512 & 8 & 87.5095 & 5 & 5.2957 & 9 & 1.6645 & 7 & 9.38710 & 7 & 0.5554 & 9 & 0.7833 & 8 \\
\hline Egarch-N & 1.4102 & 3 & 95.5747 & 10 & 5.2121 & 2 & 1.5346 & 4 & 8.84040 & 4 & 0.8871 & 13 & 0.8333 & 2 \\
\hline Egarch-t & 1.3958 & 1 & 93.8165 & 7 & 5.2106 & 1 & 1.5242 & 3 & 8.75230 & 3 & 0.8556 & 11 & 0.8333 & 2 \\
\hline Egarch-GED & 1.4003 & 2 & 95.2004 & 8 & 5.2136 & 3 & 1.5373 & 5 & 8.84360 & 5 & 0.8859 & 12 & 0.8333 & 2 \\
\hline Gjr-garch-N & 2.0831 & 11 & 101.1884 & 11 & 5.3156 & 11 & 1.8032 & 10 & 10.62690 & 10 & 0.4039 & 2 & 0.7833 & 8 \\
\hline Gjr-garch-t & 2.2168 & 13 & 113.8863 & 13 & 5.3376 & 13 & 1.8748 & 13 & 11.22480 & 13 & 0.4133 & 5 & 0.8000 & 6 \\
\hline Gjr-garch-ged & 2.1429 & 12 & 107.2969 & 12 & 5.3256 & 12 & 1.8339 & 12 & 10.88700 & 12 & 0.4079 & 4 & 0.8000 & 6 \\
\hline Mrs-garch-N & 1.9057 & 6 & 87.1919 & 4 & 5.2639 & 6 & 1.6939 & 8 & 9.83390 & 9 & 0.3783 & 1 & 0.8500 & 1 \\
\hline Mrs-garch-2t & 1.6556 & 5 & 70.3567 & 2 & 5.2385 & 5 & 1.3956 & 1 & 7.43980 & 1 & 0.4352 & 7 & 0.7833 & 8 \\
\hline Mrs-garch-t & 2.0646 & 10 & 95.3080 & 9 & 5.2887 & 8 & 1.8076 & 11 & 10.65460 & 11 & 0.4069 & 3 & 0.8333 & 2 \\
\hline Mrs-garch-ged & 1.6434 & 4 & 68.9504 & 1 & 5.2337 & 4 & 1.4007 & 2 & 7.53820 & 2 & 0.4210 & 6 & 0.7833 & 8 \\
\hline
\end{tabular}


Am. J. of Economics and Business Administration 4 (1): 84-93, 2012

Panel D: Result loss function of out-of-sample with forecasting volatility for twenty-two days ahead. (A month)

\begin{tabular}{|c|c|c|c|c|c|c|c|c|c|c|c|c|c|c|}
\hline Model & MSE1 & $\mathrm{R}$ & MSE2 & $\mathrm{R}$ & QLIKE & $\mathrm{R}$ & MAD1 & $\mathrm{R}$ & MAD2 & $\mathrm{R}$ & HMSE & $\mathrm{R}$ & SR & $\mathrm{R}$ \\
\hline Garch-N & 14.1768 & 60 & 913.3033 & 60 & 6.314 & 30 & 4.1168 & 60 & 29.774 & 6 & 0.6512 & 40 & 0.5500 & 20 \\
\hline Garch-t & 14.8896 & 80 & 969.6524 & 80 & 6.346 & 50 & 4.2464 & 80 & 31.2089 & 8 & 0.66 & 80 & 0.5500 & 20 \\
\hline Garch-GED & 14.5087 & 70 & 933.3108 & 70 & 6.3291 & 40 & 4.1817 & 70 & 30.4736 & 7 & 0.6565 & 60 & 0.5500 & 20 \\
\hline Egarch-N & 9.5602 & 10 & 631.9223 & 10 & 6.5527 & 11 & 4.0874 & 30 & 27.1309 & 3 & 4.9652 & 12 & 0.5500 & 20 \\
\hline Egarch-t & 9.6971 & 30 & 635.4651 & 20 & 6.5539 & 12 & 4.0956 & 40 & 27.212 & 4 & 4.9013 & 11 & 0.5500 & 20 \\
\hline Egarch-GED & 9.6581 & 20 & 637.1163 & 30 & 6.5726 & 13 & 4.1044 & 50 & 27.2486 & 5 & 5.0823 & 13 & 0.5500 & 20 \\
\hline Gjr-garch-N & 17.9597 & 11 & 1377.439 & 11 & 6.4293 & 80 & 4.5093 & 11 & 34.8962 & 11 & 0.6511 & 30 & 0.5167 & 90 \\
\hline Gjr-garch-t & 18.6557 & 13 & 1439.5115 & 13 & 6.4532 & 10 & 4.6106 & 13 & 36.1021 & 13 & 0.6587 & 70 & 0.5000 & 10 \\
\hline Gjr-garch-ged & 18.2373 & 12 & 1392.524 & 12 & 6.4384 & 90 & 4.5515 & 12 & 35.3763 & 12 & 0.6547 & 50 & 0.5000 & 10 \\
\hline Mrs-garch-n & 16.7158 & 10 & 1247.1304 & 10 & 6.4006 & 60 & 4.3003 & 90 & 32.5696 & 90 & 0.6279 & 10 & 0.5500 & 20 \\
\hline Mrs-garch-2t & 12.2903 & 40 & 651.7878 & 40 & 6.2225 & 10 & 3.6891 & 10 & 24.9944 & 10 & 0.737 & 10 & 0.5000 & 10 \\
\hline Mrs-garch-t & 16.687 & 90 & 1224.4922 & 90 & 6.4033 & 70 & 4.3627 & 10 & 33.1213 & 10 & 0.6402 & 20 & 0.6333 & 10 \\
\hline Mrs-garch-ged & 12.5857 & 50 & 686.0672 & 50 & 6.2299 & 20 & 3.7129 & 20 & 25.321 & 20 & 0.7226 & 90 & 0.5000 & 10 \\
\hline
\end{tabular}

But $\mathrm{a}_{0}, \mathrm{a}_{1}$ and $\beta_{1}$ are insignificantly different in some states. All models display strong persistence in volatility ranging from $0.5842-0.9619$, that is, volatility is likely to remain high over several price periods once it increases.

In-sample evaluation: We use various goodness-of-fit statistics to compare volatility models. These statistics are Akaike Information Criteria (AIC), Schwarz Bayesian Information Criteria (SBIC) and Loglikelihood (LOGL) values. In Table 6, the results of goodness-of-fit statistics and loss functions:

Loss functions:

$$
\begin{aligned}
& \operatorname{MSE}_{1}=\frac{1}{\mathrm{n}} \sum_{\mathrm{t}=1}^{\mathrm{n}}\left(\sigma_{\mathrm{t}+\mathrm{K}}-\sqrt{\mathrm{h}_{\mathrm{t}, \mathrm{K}}}\right)^{2}, \\
& \mathrm{MSE}_{2}=\frac{1}{\mathrm{n}} \sum_{\mathrm{t}=1}^{\mathrm{n}}\left(\sigma_{\mathrm{t}+\mathrm{K}}^{2}-\mathrm{h}_{\mathrm{t}, \mathrm{K}}\right)^{2} \\
& \mathrm{QLIKE}^{2} \frac{1}{\mathrm{n}} \sum_{\mathrm{t}=1}^{\mathrm{n}}\left(\ln \left(\mathrm{h}_{\mathrm{t}, \mathrm{K}}\right)-\frac{\sigma_{\mathrm{t}+\mathrm{K}}^{2}}{\mathrm{~h}_{\mathrm{t}, \mathrm{K}}}\right), \\
& \mathrm{MAD}_{1}=\frac{1}{\mathrm{n}} \sum_{\mathrm{t}=1}^{\mathrm{n}}\left|\sigma_{\mathrm{t}+\mathrm{K}}-\sqrt{\mathrm{h}_{\mathrm{t}, \mathrm{K}}}\right|, \\
& \mathrm{MAD}_{2}=\frac{1}{\mathrm{n}} \sum_{\mathrm{t}=1}^{\mathrm{n}}\left|\sigma_{\mathrm{t}+\mathrm{K}}^{2}-\mathrm{h}_{\mathrm{t}, \mathrm{K}}\right|, \\
& \mathrm{HMSE}^{2}=\frac{1}{\mathrm{n}} \sum_{\mathrm{t}=1}^{\mathrm{n}}\left(\frac{\sigma_{\mathrm{t}+\mathrm{K}}^{2}}{\mathrm{~h}_{\mathrm{t}, \mathrm{K}}}-1\right)^{2}
\end{aligned}
$$

For all volatility models are presented. According to SBIC, the EGARCH model with GED-distribution performs best in modeling the SET Index volatility. However, the MSE1 and MSE2 suggest that the EGARCH with a $\mathrm{t}$ - distribution performs best in SET Index volatility. Also AIC and LOGL suggest that the MRS-GARCH-2t performs best in SET Index volatility. MAD1, MAD2 and HMSE suggest that the MRSGARCH-t performs best in SET Index volatility and in QLIKE the MRS-GARCH with GED-distribution performs best in SET Index volatility.
Forecasting volatility in out-of-sample: We investigate the ability of MRS-GARCH and GARCH type models to forecast volatility of the SET Index in out-of-sample.

In Table 7, we present the results of loss function of out-of-sample with forecasting volatility for one day ahead, five days ahead (a week), ten days ahead (two weeks) and twenty-two days ahead (a month). We found the GARCH-type models perform best in the short term (one day and a week) for forecasting volatility of the SET Index. Additionally, we have reported a particular sign-test, the Success Ratio (SR), i.e.:

$$
\begin{aligned}
& \mathrm{SR}=\frac{1}{\mathrm{n}} \sum_{\mathrm{j}=1}^{\mathrm{n}} \mathrm{I}_{\left\{\hat{\sigma}_{\mathrm{t}+\mathrm{j}, 1}^{2} \cdot \overline{\mathrm{h}}_{\mathrm{t}+\mathrm{j}, 1}>0\right\}} \text { where I is indicator function } \\
& \hat{\sigma}_{\mathrm{t}+\mathrm{j}, 1}^{2}=\sigma_{\mathrm{t}+\mathrm{j}, 1}^{2}-\bar{\sigma}_{\mathrm{t}, 1}^{2} \text { and } \hat{\mathrm{h}}_{\mathrm{t}+\mathrm{j}, 1}=\mathrm{h}_{\mathrm{t}+\mathrm{j}, 1}-\overline{\mathrm{h}}_{\mathrm{t}, 1}
\end{aligned}
$$

The SR test is simply the fraction of volatility forecasts that have the same sign as volatility realizations. From the table we can see that the GARCHtype models do a great job in correctly predicting the sign of the future volatility in the short term.

On the other hand, we found that the MRSGARCH models perform best in the long term (two weeks and a month) for forecasting the volatility of the SET Index. Also, the SR test MRS-GARCH models do a great job in correctly predicting the future volatility in the long term.

\section{DISCUSSION}

For forecasting volatility in the long term in SET Index, the MRS-GARCH models perform best.

\section{CONCLUSION}

In this study, we modeled the returns of the SET Index by mean equation with the day of the week effect 
and the autoregressive moving-average order $\mathrm{p}$ and $\mathrm{q}$ (ARMA $(p, q))$ and forecasted the volatility of the SET Index by the GARCH, EGARCH, GJR-GARCH and MRS-GARCH models. Moreover we compared their volatility forecast performance with one day, one week, two weeks and one month returns.

Friday is day effect of the SET Index. Displays the first estimate of return equation with $\operatorname{ARMA}(3,3)$. The GARCH-type models perform best in the short term (one day and a week). On the other hand, the MRSGARCH models perform best in the long term (two weeks and a month) for forecasting volatility of the SET Index.

For further study, three or four volatility regime settings can be considered rather than two-volatility regimes or using Markov Regime Switching with other volatility models e.g., EGARCH, GJR. In addition, the performance of the MRS-GARCH models can be compared in terms of their ability to forecast Value at Risk (VaR) for long and short positions.

\section{ACKNOWLEDGEMENT}

This research is (partitioned) supported by the Thailand research fund BRG 5180020.

\section{REFERENCES}

Apolinario, R.M.C., O.M. Santana and L.J. Sales, 2006. Day of the week effect on European stock markets. Int. Res. J. Finan. Econ.

Easton, S. and R. Faff, 1994. An Examination of the robustness of the day of the week effect in Australia. Applied Finan. Econ., 4: 99-110.

Gray, S.F., 1996. Modeling the conditional distribution of interest rates as a regime-switching process. J. Finan. Econ., 42: 27-62. DOI: 10.1016/0304405X(96)00875-6
Hamilton, J.D., 1989. A new approach to the economic analysis of nonstationary time series and the business cycle. Econometrica, 57: 357-384. DOI: $10.2307 / 1912559$

Hamilton, J.D., 1990. Analysis of time series subject to changes in regime. J. Econ., 45: 39-70.

Kim, C.J. and C.R. Nelson, 1999. State-space Models With Regime Switching: Classical and GibbsSampling Approaches With Applications. 1st Edn., MIT Press, Cambridge, MA., ISBN-10: 0262112388, pp: 297.

Klaanssen, F., 2002. Improving GARCH volatility forecasts with regime-switching GARCH. Empirical Econ., 27: 363-394. DOI: 10.1007/s001810100100

Kyimaz, H. and H. Berument, 2001. The day of the week effect on stock market volatility. J. Econ. Finan., 25: 181-193. DOI: 10.1007/BF02744521

Klaassen, T., 2002. Out of Balance: Serotonergic Studies in Affective Disorders. 1st Edn., Universitaire Pers Maastricht, Maastricht, ISBN10: 9052783160 , pp: 167.

Marcucci, J., 2005. Forecasting stock market volatility with regime-switching GARCH model. University of California.

Miralles, J.L.M. and M.D.M.M. Quiros, 2000. An empirical analysis of the weekday effect on the Lisbon stock market over trading and non-trading periods. Portuguese Rev. Finan. Markets, 3: 5-14.

Ulussever, T., I.G. Yumusak and M. Kar, 2011. The day-of-the-week effect on the Saudi stock exchange: A non-linear garch analysis. J. Econ. Soc. Stud., 1: 9-23. 